\title{
Perversão nas mulheres ou perversão feminina. Uma questão de sexuação*1
}

\author{
Patrick Martin-Mattera*2
}

A questão do sexo da perversão resulta de uma problemática necessariamente social. Perversão polimorfa, perversão patológica, perversão estrutural, são as três modalidades de abordagem que nos interessam aqui para cruzar as noções de sexuação e de perversão. A perversão tem um gênero, isto é, pertence especificamente a um estilo masculino ou feminino ou existe por um lado uma perversão masculina e, por outro, uma perversão feminina?

Palavras-chave: Perversão, sexuação, feminilidade, psicanálise

*1 Conferência proferida na Universidade Católica de Pernambuco - Unicap (Recife, $\mathrm{PE}, \mathrm{Br})$ no Colóquio Internacional sobre a Metapsicologia da Perversão. Usos Sociais da Perversão, realizado em Recife (PE), nos dias 26, 27 e 28 de agosto de 2013.

*2 Faculdade Pernambucana de Saúde - FPS (Recife, PE, Br). 


\section{ARTIGOS}

\section{Introdução}

A clínica da perversão é hoje geralmente conhecida principalmente como masculina e fálica, ainda que a sua história mostre que pode, em determinados momentos, estar melhor repartida entre os dois sexos. Krafft-Ebing e Freud, mesmo sendo tão diferentes, não faziam, nem um nem outro, sexismo clínico no que diz respeito à perversão. Contudo, certos clínicos contemporâneos põem em dúvida uma perversão que seria "toda fálica", abrindo assim uma via de reflexão que corresponde a observações clínicas que ficaram ou despercebidas ou enigmáticas. A perversão pertence a um gênero, pertence especificamente a um estilo masculino ou feminino, ou então há, por um lado, uma perversão masculina e, por outro, uma perversão feminina?

A noção de estrutura psíquica em psicanálise modificou profundamente a definição das patologias, desde os "Três ensaios sobre a teoria sexual", onde Freud (1905/2006, p. 105) escreve que as neuroses formam um conjunto que vai das diversas manifestações da doença até à saúde propriamente dita. ${ }^{1}$ Hoje, admitimos bastante facilmente isso porque concebemos a organização do psiquismo segundo o modelo da estrutura neurótica, mas temos já mais dificuldade em admitir - damo-nos bem conta em psiquiatria - que a noção de estrutura psicótica, tão nitidamente desenvolvida por Lacan por meio dos conceitos de foraclusão (Lacan, 1955-1956/1981) e de sinthoma (Lacan, 1975-1976/2005), implica, também ela, a ideia de que podemos depender dessa estrutura sem contudo estar doente. Que podemos dizer, então, desta última ideia segundo a qual poderíamos estar em boa saúde, dizendo mesmo "normal", e ser estruturado segundo uma modalidade perversa? Isto parece muito mais delicado e paradoxal, pois o termo de perversão transmite implicações morais, jurídicas e mórbidas. O sinal mais claro dessa dificuldade em admitir uma ancoragem coletiva no registro da perversão, contudo demonstrada desde 1905 com a publicação dos "Três ensaios", encontra-se, pelo menos, nos elementos seguintes: isolamento da estrutura perversa e assimilação desta a uma patologia, ideia espalhada segundo a qual os sujeitos perversos não consultam, resistência em identificar a perversão nas mulheres.

${ }^{1} \mathrm{O}$ texto alemão diz isto: "die Neurosen von allen ihren Ausbildungen her in lückenlosen Reihen zur Gesundheit ablinken”. 


\section{Uma estrutura exclusiva ou não?}

Muitos autores, mesmo a maior parte deles, isolaram, com razão, a estrutura perversa da estrutura neurótica. Citemos somente Joël Dor (1987): "Freud insiste (...) no fato de que a distinção radical entre as perversões e as neuroses supõe uma diferença de ordem topográfica e estrutural" (p. 129; grifo nosso), ou Hervé Castanet (2012) "podemos afirmar que existe uma estrutura freudiana de perversão" (p. 67). Todos estes autores apoiam-se, em particular, na ideia de que na medida em que Lacan, na perspectiva aberta com efeito por Freud (1927) com o texto sobre o fetichismo e o da clivagem do eu (Freud, 1938), definiu a perversão como uma terceira estrutura, daí resulta que os perversos são fundamentalmente diferentes dos neuróticos, e é aí, pois, que nós introduzimos um ponto de interrogação, exclusivamente separado deles. Em outras palavras, é fácil demais, neste sentido, pensar que há entre os neuróticos e os perversos uma barreira inultrapassável, idêntica àquela que existe entre as neuroses e as psicoses. Esta opinião pode parecer criticável por várias razões. Ela retoma de uma forma indireta o mesmo distanciamento que efetuava a sociedade do fim do século XIX promovendo a teoria da degenerescência, contudo completamente desfeita por Freud. A isto junta-se o fato de que a distinção é muitas vezes feita, nos nossos meios lacanianos, entre os sinais perversos, supostos serem aferentes em particular aos neuróticos e a organização perversa própria aos sujeitos estruturados como tal. Ora, mesmo se Lacan faz questão em destacar, com efeito, as especificidades da estrutura perversa, nada indica verdadeiramente, nos seus propósitos ou nos seus textos, que entre os neuróticos e os perversos não possam existir passarelas. E ainda mais, não nos dá ele uma pista quando declara que "o débil mental, submetido à psicanálise, torna-se sempre um canalha" (Lacan, 1973, p. 3). Sabendo que ele tinha, repetidamente, dito antes que os canalhas em análise acabavam "estúpidos que nem portas" (Lacan, 1972), o que deduzir daí? O débil mental está aí bem definido como o falasser, o sujeito atormentado pela sua condição humana que aqui pode ser, precisamente, considerado o neurótico corrente. E o canalha, quanto a ele, pode ser aproximado então do sujeito perverso (de estrutura) mesmo se alguns como Patrick Valas (2012), o contestam $^{2}$ - visto que Lacan (1970) diz que "toda a canalhada assenta sobre isto, querer ser o Outro, quero dizer, o grande Outro de alguém, aí onde se desenham as figuras onde o seu desejo será captado" (p. 68). Desta maneira, Lacan, assim como Freud, põe em evidência a especifidade da organização perversa: ele indica

${ }^{2}$ Texto no qual Patrick Valas compara a canalhada à perversidade e não à perversão (sexual). Mas é esta distinção exclusiva? 
que é preciso distinguir com o maior rigor o ato perverso - baseando-se no gozo - do ato neurótico - que põe em jogo o efeito do desejo (Lacan, 1967, sessão de 7 junho de 1967). Mas isto não impede de pensar que determinadas condições permitem, no decorrer do trabalho sobre a posição subjetiva, ter em vista uma ultrapassagem. Contudo, esta definição - uma entre muitas — do sujeito perverso tem a vantagem de não insistir sobre uma ou outra das posições sexuadas, deixando pensar que se a perversão é bem uma estrutura, ela não poderia, assim, estar reservada unicamente aos representantes machos dos falassers.

\section{Há verdadeiramente ausência de pedido?}

A perversão estrutural deve, em princípio, provocar no sujeito um relativo bem-estar - real ou ilusório - , o que não leva muitas vezes esses sujeitos a consultarem (como observa por exemplo De M'Uzan (1972), Korff-Sausse (2003), ou Hiltenbrand (2009). Aliás, os que nós recebemos vêm, por vezes, obrigados por uma razão qualquer, medo da sanção ou da decisão da justiça. Daí advém um relativo impasse clínico: se não há observações ou há muito poucas, como construir uma teoria que faça sentido? Face a esta afirmação muitas vezes constatada, podemos perguntar se os clínicos não seriam aqui vítimas de uma definição demasiadamente limitada da perversão, que os impediria, contudo, de ter em consideração certos elementos presentes na sua clínica. A linha que aqui pretendemos defender desenvolve essa ideia, apoiando-se no fato de que a perversão põe em jogo, como veremos, várias dimensões através das quais o sujeito, em posição masculina ou em posição feminina, consegue ancorar uma procura de gozo - não forçosamente consciente, aliás. Esta procura de gozo atravessa-o, por vezes, como uma resposta ao seu mal-estar e então, para ele, pode tomar a forma - com ou sem razão — de uma saída terapêutica. Nas curas psicanalíticas, os elementos perversos que entram no jogo não são raros. E estes elementos não são somente sinais de fixação à sexualidade infantil nem fantasmas de neuróticos imitando a perversão (scénarii com dois consentidores, por exemplo). Eles refletem nos homens como nas mulheres que os relatam — mesmo se eles não vieram no começo consultar por causa disso - uma evolução do seu posicionamento psíquico no qual a perversão intervém como uma solução, por vezes momentânea.

\section{A dificuldade em descobrir a perversão feminina}

Conhecemos a alta resistência para identificar em clínica uma perversão feminina, e mesmo perversões nas mulheres — o que não é a mesma coisa - 
e por isso todas as dificuldades em considerar que a estrutura perversa possa dizer respeito às mulheres. Os exemplos de autores apoiando essas ideias são numerosos. Granoff e Perrier, em 1964, pensam que "à parte a homossexualidade (...) via particular onde penetra a sexualidade feminina sem aí se pervertir, não há na mulher, propriamente falando perversões sexuais" (p. 89), ideia que em 1987 Joël Dor (p. 259) retoma palavra por palavra. Didier Castanet afirma em 2003 que "clinicamente, encontra-se sempre a perversão do lado masculino" (p. 93). François Leguil declara, em 2009, que "é clássico notar que as perversões se declinam muito melhor e com uma frequência superior no masculino do que no feminino" (Leguil, 2012, p. 93). Aliás, o próprio Lacan (1959) afirma "há menor frequência de perversão na mulher" (sessão de 17 de junho). Talvez. É um fato comprovado que a perversão ocasionou teorias múltiplas, por vezes confusas, ${ }^{3}$ por vezes luminosas e organizadoras, no seio das quais impôs-se há muito tempo, a ideia de que ela dependia, antes de tudo, de uma posição fálica dominadora e masculina, o que hoje começa a ser posto em dúvida, como o faz, por exemplo, Alain Abelhauser (2013). Este avanço apoia-se sobre o ensino de Lacan, graças ao qual podemos constatar que a organização psíquica perversa está ligada com a posição do sujeito na ordem da sexuação e não somente "agarrados" à contigência do seu sexo anatômico. Parece, com efeito que, para muitos clínicos, ser anatomicamente homem ou mulher tenha tido um papel muito importante, em detrimento da escolha psíquica da sexuação que a psicanálise, desde 1973 pelo menos, ${ }^{4}$ tinha porém propulsado ao primeiro plano.

Contudo, alguns psicanalistas privilegiam a hipótese que, se algumas mulheres são perversas, é porque a sua inscrição na sexuação far-se-ia em posição masculina. É a ideia defendida por Didier Castanet (2003) quando ele se interroga "se podemos falar de 'perversão feminina' uma vez que estabelecemos que ser homem não é um fato de anatomia mas de posição subjetiva" (p. 94), ou Colette Soler (2003) quando ela fala de "perversão masculina generalizada" (p. 170 e 174). Para eles a perversão, como tal, é masculina, isto definindo o seu "gênero" estrutural. Mas a clínica dos sujeitos perversos é suficientemente complexa para que esta afirmação

${ }^{3}$ Basta ler, por exemplo, esta passagem do livro de Dominique Klopfert (2010), para se aperceber imediatamente: "O termo [de perversão] é muitas vezes utilizado sem distinguir a mínima os sentidos seguintes: a estrutura perversa, os sintomas ou sinais perversos, a perversão polimorfa (freudiana), a perversão ligada ao objeto a (lacaniana), a perversão moral de onde a perversão do laço ou perversão narcísica, e as perversões sexuais (A. Eiguer)", e ela acrescenta as perversões transitórias do adolescente, os acting-out de caráter perverso e as perversões sociais (p. 264).

${ }^{4}$ Graças a J. Lacan (1973) no seu Seminário Mais, ainda. 
seja relativizada: uma outra hipótese, que é a que defendemos, é que há uma maneira masculina (fálica) e uma maneira feminina (não todo) de ser perverso(a).

A historiadora Sylvie Chaperon (2008), que trabalhou sobre os fundamentos na França da medicina do sexo, observa que "as masturbadoras, as erotômanas, e as ninfômanas formam legiões, mas os psiquiatras da segunda metade do século XIX elaboram a nomenclatura das perversões com casos exclusivamente masculinos. Eles deploram por não poderem conhecer melhor a intimidade dos seus contemporâneos" (p. 13). Numa sociedade que intimava ao pudor (p. 24), podemos falar da dificuldade que presidiu a localização das perversões no momento em que estas foram elaboradas pelos psiquiatras do século XIX, mesmo se alguns grandes nomes da psiquiatria alemã ou inglesa tenham podido, todavia, evocar a sexualidade e a perversão nas mulheres, tais como Havelock Ellis, Magnus Hirschfeld, ou Krafft-Ebing (1923) que cita na sua Psicopatia sexualis numerosos casos de mulheres perversas. Esta dificuldade já desapareceu hoje? Nós não acreditamos e, mesmo que a situação tenha mudado, a reserva respeitante à sexualidade não está, apesar disso, suprimida: não é muito frequente, nas curas, que os analisandos ou as analisandas levem muito tempo para fazer uma descrição detalhada das suas fantasias e/ou dos seus agires sexuais.

\section{Pequeno percurso de autores sobre a perversão nas mulheres}

Freud não sublinha diferenças entre homens e mulheres no que diz respeito à questão da perversão porque a definição que ele dá, desde o começo, universaliza a noção, visto que ele faz da perversão um dos elementos principais da construção psíquica da criança, considerada como perversa polimorfa. Em seguida, os exemplos que ele toma para tratar da organização psíquica perversa possuem muitas mulheres: no texto "Uma criança é espancada" (Freud, 1919), o fantasma de fustigação pertence tanto aos homens como às mulheres ("quatro mulheres [e] dois homens" (p. 123), o texto "Psicogênese de um caso de homossexualidade feminina" (Freud, 1920) põe em evidência, com certeza, uma mulher etc. Mas é verdade que a partir de 1927, quando ele evoca o fetichismo, os exemplos escolhidos são masculinos.

Lacan (1963) considera que a posição do sujeito perverso é de se fazer objeto para o Outro (p. 774) e o que ele enuncia sobre a perversão repousa sobre uma concepção estrutural, tanto do lado da organização psíquica perversa como da posição do sujeito no registro da sexuação. Ele dá a propósito da perversão e das mulheres os seguintes elementos: 
R E V I $S$ S T A

LATINOAMERICANA

DE PSICOPATOLOGIA

F U N D A E N T A L

- há menos perversão nas mulheres que nos homens e isto explica-se através das relações com as crianças ( $O$ desejo e a sua interpretação [Lacan, 1959, sessão de 17 de junho]);

- o fetichismo feminino esconde-se atrás do fato que "ela própria assume o papel do fetiche" (Propósitos diretivos para um congresso sobre a sexualidade feminina [Lacan, 1960, p. 731]);

- o suposto masoquismo feminino não é mais do que um fantasma do desejo do homem (Propósitos diretivos para um congresso sobre a sexualidade feminina, [Lacan, 1960, p. 731]);

- Enfim, ele acrescenta que "interrogar-se sobre o gozo feminino (...) é já abrir a porta a todos os atos perversos" (Lógica do fantasma [Lacan, 1967, sessão de 7 de junho]).

Lacan (1967) dá-nos também uma preciosa indicação logo que diz que na perversão "todo o corpo não foi tomado no processo de alienação" (sessão de 30 de maio). Esta não alienação parcial ao Outro, no registro do significante, acorda à clivagem uma importância muito maior e é sobre este ponto que nós avançaremos mais tarde.

Piera Aulagnier, em 1967, é uma das primeiras psicanalistas a falar especificamente da questão da perversão feminina, como paixão, no seu texto sobre a feminilidade e seus avatares, onde ela indica que a relação da mulher com a perversão é o masoquismo (p. 63) que contrariamente ao do homem que se situa entre "gozo ou não gozo", o véu da mulher "situa-se entre "prazer e dor"” (p. 66), que a homossexualidade feminina está marcada pela rivalidade das parceiras em relação com a feminilidade, considerada aqui como um equivalente fálico (p. 70), e enfim que o nó da feminilidade é a dimensão do engano derivado da descoberta da castração da mãe, que institui o parecer e a mascarada (p. 72).

Joël Dor, em 1987, pensa que nas mulheres que se encontrariam confrontadas ao real da ausência fálica, não haveria perversão organizada no plano estrutural. E se qualquer coisa faz duvidar disso, tratar-se-á sobretudo de vestígios da "perversidade" polimorfa da criança (p. 265) através da qual as mulheres podem tornar-se instrumento da perversão dos homens. Assim, Dor pensa que se as mulheres podem, por vezes, parecer perversas, trata-se somente de perversões da libido e não de perversões estruturais e faz a lista delas: homossexualidade, narcisismo, maternagem e identificação ao objeto da paixão de um homem.

Daniel Sibony (1987) desenvolve ideias sobre a perversão em que uma parte reúne patologias e/ou comportamentos aparentemente diversificados: o extremismo religioso, a toxicomania e sobretudo a anorexia, própria principalmente das moças (a anorexia tinha sido apresentada anteriormente, em 1972, como uma perversão 


\section{ARTIGOS}

"pulsional" por Evelyne e Jean Kestemberg e Simone Decobert (1972)). Sibony alarga o conceito de perversão às mulheres, mas dá-lhe uma dimensão social que será depois grandemente amplificada por J-P. Lebrun (2007) e C. Melman (2005).

François Sirois em 1999, num artigo que recenseia particularmente a evolução e a modificação da noção de fetichismo, diz que "a mulher manifesta a perversão da sua libido pela mudança narcísica onde ela procura (...) fazer desaparecer o objeto parcial como manifestação do desejo identificando-se a ele" (p. 291). Assim, a mulher identifica-se ao falo e, através disso, visa "o desejo de ser admirada em vez de ser amada, exercendo uma fascinação mais do que um atrativo, inacessível e impenetrável" (p. 291). Ele continua fazendo uma distinção onde o corpo intervém como critério determinante: a perversão na mulher depende do que ela faz ao seu próprio corpo, enquanto o homem procura impor ao corpo do outro este objeto parcial que é o fetiche.

Alain Abelhauser, em 2013 em Mal de femme, tem uma posição muito original, visto que identifica um grupo de patologias, a que chama "mal proteiforme" tal como a anorexia mental, mas também as patomimias, as síndromes de Münchhausen, de Lasthénie de Ferjol, de Meadow, e ainda outros que se parecem com este, como pertencendo a uma forma feminina da perversão, que seria "não somente em referência à função fálica, mas também ao Outro gozo" (p. 304).

\section{Diferentes manifestações da perversão nas mulheres}

Assim, e para resumir o que, na literatura, domina como manifestações da perversão nas mulheres, eis a síntese da nossa recolha: a relação com as crianças ou maternagem, o fato de que a mulher assume o papel do fetiche (ela é "fetichizada" dizia Granoff e Perrier [1964, p. 92]), ${ }^{5}$ o fato que ela seja masoquista (o que Lacan relativiza), determinadas homossexualidades, a dimensão fundamental do engano, o narcisismo e a sua inscrição corporal, a identificação com o objeto da paixão de um homem, a toxicomania e o alcoolismo, a anorexia, e, por fim, tudo o que Abelhauser chama de "mal proteiforme" (síndromes tipo Münchhausen, Meadow ou Lasthénie de Ferjol). Essas afecções, a nosso ver, dividem-se em dois grupos: o primeiro pertence ao registro da posição masculina, isto é, fálica ou não fálica (o que se opõe ao fálico,

5 "Se ela não é fetiche, ela pode ser 'fetichizada', devido à dialética do ser e do ter" (Granoff e Perrier, 1964, p. 92). 
R E V I I S T A

LATINOAMERICANA

DE PSICOPATOLOGIA

F U D A M E T A L

fazendo disso a sua referência), o segundo grupo pertence à posição feminina, o que chamamos "extra fálico" (Martin-Mattera, 2005); em outras palavras, tudo o que pertence ao Outro gozo (outro que fálico) e que procede do "não todo" feminino. Notaremos, contudo, que as perversões femininas "históricas" salientadas por Sylvie Chaperon (2008) no seu estudo bastante documentado se dividem assim, de maneira muito mais fenomenal e clássica: onanismo, ninfomania, erotomania, anafrodismo, frigidez e impotência, bestialidade, zoofilia, necrofilia, exibicionismo, safismo, tribalismo e inversão sexual, fetichismo (dois casos, apesar de tudo), pedofilia.

Mas o que é sobretudo importante reter, é que a perversão das mulheres não é a perversão feminina a qual se relaciona com a especificidade da posição psíquica feminina (na ordem da sexuação, é um posicionamento inconsciente), enquanto a primeira, a perversão das mulheres, pode também apoiar-se sobre a anatomia, sobre a posição social, sobre a condição feminina. Esta, parece-nos provocar a diluição eventual da perversão na cultura e no social. Por exemplo, o exibicionismo pode ser exacerbado no fato de ser atirante, vestido(a) de tal ou tal maneira, de ser provocante, ou, pelo contrário, como uma alusão, ligeira e modesta etc. E sobre este assunto temos o que Aulagnier lembrava, no seguimento de Joan Rivière (1929) e de Lacan (1958), sobre o parecer e a mascarada. ${ }^{6}$ Da mesma maneira, as relações de sedução podem deslizar pouco a pouco, para laços onde se desenham dominantes e dominados, cujas funções se trocam sem que forçosamente eles se apercebam.

Mas o que é, então, esta posição psíquica feminina, onde a perversão poderia inscrever-se também, sem contudo ser fálica, e como apreender a importância clínica da sexuação sobre a perversão?

Para introduzir este debate, gostaríamos de evocar, rapidamente, algumas situações clínicas nas quais um determinado aspecto da estrutura perversa é posto em evidência, isto é, o da clivagem, tal como aparece no que alguns autores chamaram perversidade (Henri Ey, 1950), relação perversa (Granoff e Perrier, 1964), engano (Piera Aulagnier, 1967), perversão afetiva (Christian David, 1972), perversão narcísica (Paul-Claude Racamier, 1986 e 1987) ou ainda simulação (Abelhauser, 2013). Estas situações implicam de cada vez uma duplicidade do sujeito, uma característica bifrons, como Janus, um sujeito com uma cara dupla, mulher ou homem em posição feminina, onde se poderá reconhecer igualmente o ou a parceira que trai sem razão aparente ("contudo não tenho nada a censurar-lhe"), o amigo(a) tão gentil da família que se revela em seguida ser um monstro dissimulado, o marido ou a mulher, levando uma vida dupla durante tantos anos, o ou a falsa doente que engana há tanto tempo todos à sua volta e os médicos, o empregado(a) modelo culpado(a) de apropriação indébita, o trapaceiro(a) tão sedutor ou tão sedutora, e outras situações tendentes para a impostura. Estas pessoas põem as suas vítimas numa situação nas quais elas são bruscamente confrontadas a um gozo que elas não desejam - os lacanianos dizem também: à sua divisão subjetiva - elas 


\section{ARTIGOS}

põem-nas em confronto, de fato, a um gozo Outro, um gozo não fálico onde a sexualidade desempenha um papel acessório - quando ela desempenha algum. Mas, de cada vez para a sua vítima, o ator perverso vem ocupar o lugar ilusório do objeto ideal de um fantasma prometedor de prazer que, no fim do jogo, precipita o parceiro no abismo de uma perplexidade ou de uma dor sem nome.

Nós propomos, agora, formalizar esta inscrição particular no campo da perversão.

\section{A sexuação e a perversão}

Revisando

As fórmulas da sexuação, que encontramos reunidas num quadro do seminário Mais, ainda (Lacan, 1973, p. 73), formalizam a relação do sujeito à função fálica, quer dizer, à condição humana, submetida à lei do significante (a alienação) e ao seu regime de oposição (a separação). Esta condição humana, que ameaça sempre o sentimento de derelição, é o que a psicanálise chama de castração. Estas fórmulas, constituídas cada uma de duas proposições colocadas uma acima da outra e funcionando numa relação de oposição determinativa (uma só tem sentido em relação à outra), mostram que a sexuação é uma "escolha" psíquica: ser homem ou ser mulher não depende unicamente da contigência biológica, mas pertence ao compromisso psíquico do sujeito a um momento da sua história (no tempo de Édipo), momento durante o qual ele se situa como menino ou menina, em relação ao outro sexo, segundo uma modalidade que pertence à linguagem (ao logos, à lógica). Trata-se pois, neste caso, de uma tomada de independência, no que respeita ao biológico, o que explica as escolhas de objeto homossexuais, por exemplo. Mas o mais importante reside, sem dúvida, no fato de que a lógica que se exibe aqui não é só fálica: certamente, ser homem ou ser mulher pertence a um posicionamento fálico (ter ou não ter o falo), mas a posição feminina comporta também uma outra via, representada pelo símbolo $\bar{\forall} \mathrm{x}$ (não todo $\mathrm{x}$ ) em que o sujeito em posição feminina não é não todo tomado na função fálica.

\section{Posição masculina}

As condições da posição masculina apresentam-se assim: o primeiro andar (primeira proposição lógica) significa que existe um x que não está submetido à função fálica (isto pode ser, por exemplo o Pai da horda; e o segundo andar (segunda proposição lógica) que para cada um (para todo x) aplica-se a função 
fálica. Para que tenha sentido a significação fálica, é preciso - segundo o regime do significante - que isso reenvie ao seu oposto (ou seja, que uma exceção seja suposta a esta regra, por outras palavras, um escape (à função fálica).

\section{Posição masculina}

$$
\begin{array}{ll}
\exists \mathrm{x} & \bar{\Phi} \mathrm{x} \\
\forall \mathrm{x} & \Phi \mathrm{x}
\end{array}
$$

\section{Posição feminina}

As condições da posição feminina são representadas, quanto a elas, pelas duas linhas seguintes: onde o primeiro andar significa que nenhum escapa à função fálica (nada de $\mathrm{x}$ que não se encontre submetido à função fálica) e o segundo que não é não todo do sujeito (não todo $\mathrm{x}$ ) que está submetido à função fálica. E desta vez a significação fálica só tem sentido pela relação com uma outra espécie de oposto: o não todo fálico que determina um gozo Outro (só fálico para o sujeito em posição feminina).

$$
\begin{gathered}
\text { Posição feminina } \\
\bar{\exists} \mathrm{x} \quad \bar{\Phi} \mathrm{x} \\
\bar{\forall} \mathrm{x} \quad \Phi \mathrm{x}
\end{gathered}
$$

Estas relações determinam pois, para o sujeito, um lugar lógico na sexuação.

\section{Um posicionamento perverso}

Partimos da ideia de que o posicionamento do sujeito perverso que diz respeito ao funcionamento fálico (desmentido ou Verleugnung da castração da mãe) e igualmente o posicionamento no gozo Outro, requer uma operação psíquica particular. Os autores, de uma maneira muito clássica, consideram ou que os perversos são exclusivamente determinados (devido à Verleugnung) pelo registo fálico (os perversos visariam assim uma mestria fálica), ou que eles se inscrevem em posição feminina nesse gozo Outro que os determina a pôr em jogo o seu próprio 
corpo (Sirois, 1999; Abelhauser, 2013). Mas considerando as situações clínicas que evocamos antes, sentimo-nos incitados a fazer uma proposição deslocada que consiste em ligar os dois posicionamentos sexuados, o que conduz de fato a uma situação transgressiva. Para isso, partimos da frase de Lacan (1967) "todo o corpo não foi tomado no processo de alienação" (sessão de 30 maio de 1967); o que significa, pois, esta proposição? Se uma parte do corpo escapou à tomada no significante (é o que quer dizer o "processo de alienação"; isto implica que qualquer coisa do corpo - do outro ou do sujeito - escapa à lei. No caso do sujeito em posição masculina, sabemos que se trata de manter contra todas as probabilidades o falo materno, e no caso do sujeito em posição feminina, compreendemos que o que se mantém assim, diz respeito ao seu próprio corpo, à sua vida e à sua morte. Produzse, então, uma ruptura na relação com a lei, com o corpo e com os outros, que arrasta o sujeito para uma alteração da relação, alteração que é feita para verificar sistematicamente a realidade da não submissão ao registro fálico, seja afirmando a conservação da não castração (o falo materno), seja optando por um gozo Outro que em vez de reenviar, como isso deveria acontecer, à assunção da castração, reenvia desta vez ao seu contrário.

É por isso, que propomos representar assim o posicionamento perverso que se pode declinar quer a nível "masculino" quer a nível "feminino": trata-se de uma transgressão lógica, de uma anormalidade, visto que à primeira proposição masculina (existe um que não é castrado) responde a proposição feminina (não todo do sujeito está submetido à castração).

\section{Posição perversa \\ $\exists \mathrm{x} \quad \bar{\Phi} \mathrm{x}$ \\ $\bar{\forall} \quad \Phi x$}

Assim, a partir de um mesmo posicionamento, vemos emergir quer uma via de perversão masculina $-\exists \mathrm{x} \bar{\Phi} \mathrm{x}$ - quer uma via de perversão feminina $-\bar{\forall} \mathrm{x} \Phi \mathrm{x}-$ onde as proposições encontram-se, de certa forma, isoladas do seu corolário normal.

Em posição masculina, a perversão consiste pois, no isolamento da proposição superior, $\exists \mathrm{x} \bar{\Phi} \mathrm{x}$ (existe um que não é castrado, compreendido aqui como uma não o é, a mãe), proposição que, separada do seu corolário habitual, $\forall \mathrm{x} \Phi \mathrm{x}$ (todos são castrados), realiza a condição da Verleugnung (ou desmentido) da castração da mãe.

E em posição feminina, a perversão isola, desta vez, a proposição inferior $\bar{\forall} \mathrm{x}$ Fx (não todo, do sujeito está submetido à castração) que, separada do seu 
corolário habitual $\quad \bar{\exists} \mathrm{x} \quad \bar{\Phi} \mathrm{x}$ (nenhum sujeito escapa à castração), marca a clivagem do seu (Ichspaltung) que Freud tinha feito uma outra condição da perversão.

Considerando que o processo da perversão implica ao mesmo tempo a Verleugnung e a Spaltung, pensamos que fazer uma distinção entre a perversão masculina e a perversão feminina é possível se tivermos em conta a acentuação de uma das componentes deste processo. Assim, a perversão masculina acentua a Verleugnung enquanto a perversão feminina se articula à volta da Spaltung, o que não implica que a componente "secundária" seja abandonada. Tomemos dois exemplos. No caso de um fetichista, o objeto escolhido, se ele constitui o falo materno, supõe, mesmo assim, a clivagem do eu: o sujeito que rouba à sua vizinha as calcinhas e que se faz apanhar em flagrante sabe bem que realiza um ato ao mesmo tempo irrisório e proibido, mas apesar de tudo, ele faz. E no caso dessas mulheres ou desses sujeitos em posição feminina que falamos mais acima, determinados pela duplicidade ou a impostura, eles mantêm a clivagem entre o que os outros esperam deles e os seus atos, e é, sem dúvida, o que mais lhes importa, mas eles recuperam assim - de qualquer maneira antes que o segredo seja revelado um benefício secundário fálico, no interesse que eles encontram na própria situação: mais-de-gozar sexual, pecuniário, social etc. Todavia, o que na realidade está em jogo no cenário deles não é propriamente este ganho: ele reside, antes de tudo, na dupla existência que supõe e no fato de se determinar num certo registro racional: o do não todo, não todo submetido ao limite da condição humana.

\section{Conclusão}

Vimos que a questão da perversão feminina, como aliás a da perversão no feminino, não é evidente. A perversão em geral, poderíamos dizer que de qualquer modo não é fácil, sobretudo se se fala de estrutura perversa. Não ficaremos verdadeiramente surpreendidos com isso.

O que podemos concluir do que foi dito antes? Pelo menos estes três pontos:

- Primeiro, que a perversão é uma estrutura, mesmo se ela não é exclusiva, uma organização psíquica específica, distinta nisso da única realização de fantasmas tal como os neuróticos a praticam. E, como estrutura, a perversão diz respeito ao sujeito, mais exatamente o sujeito do inconsciente, porque a perversão implica também, como a neurose, a dimensão do inconsciente e não é simplesmente uma questão de vontade. Não se torna perverso quem quer.

- A seguir, confundiram, sem dúvida, durante muito tempo o processo do desmentido da castração materna com o ligamento obrigatório da perversão à dimensão fálica, excluindo, ao mesmo tempo, o conjunto das mulheres desta 


\section{ARTIGOS}

categoria estrutural. Desta forma, o que privilegiávamos era a dimensão da anatomia propriamente dita, dimensão que a aproximação lacaniana tinha contudo relativizado. Por outro lado, a história mostra que depois de ter sida considerada no século XIX muito masculina, a perversão foi em seguida alargada às mulheres e isto, sob a influência da psicanálise que, na época, dava, contudo, um lugar importante à questão anatômica ("o destino é a anatomia", dizia Freud em 1924 [p. 31]). Depois, sem dúvida por causa da distinção entre perversão polimorfa, comportamentos ou sinais perversos e estrutura perversa, a perversão foi remasculinizada pelos lacanianos, em particular, pela razão que os "verdadeiros" perversos, os que o são de estrutura, só teriam acesso a esta a partir de uma determinação fálica. Desta maneira, só poderiam ser perversos os sujeitos machos ou — e é já mais largo — os sujeitos em posição masculina, dando assim à perversão o gênero masculino. Para mais, o registro fálico declina-se do lado de o ter ou de não o ter (o falo), e também do que Freud chamava atividade masculina e passividade feminina: é por isso que alguns autores puderam dizer que os atores perversos eram os homens, enquanto as mulheres faziam o jogo de parceiro, se fetichizavam, aceitavam ser o complemento passivo da perversão masculina.

- Enfim, podemos também concluir que a perspectiva de exclusividade masculina perversa começa hoje a ser discutida, e completada, porque a posição feminina — na sexuação - ela também se abre para uma clínica da perversão, é o que tentamos descrever acima.

Com efeito, a proposição $\bar{\forall} \times \Phi x$, característica da posição feminina, pode-se interpretar - e ser interpretada pelo próprio sujeito — de duas maneiras bem distintas:

- seja sob a forma de um: "não todo do sujeito pertence ao registo fálico", o que reenvia ao extrafálico, por exemplo à posição mística de um gozo Outro,

- seja - e é a interpretação perversa - como: "não todo do sujeito está submetido à castração" o que implica então que seria possível sair daí, e o que autoriza, de certa maneira, o sujeito a um gozo não negativado segundo a expressão empregada por vezes por Lacan (1967) (sessão de 19 de abril) e sobre a qual insistia tanto Solange Faladé (1993-1994).

O gozo negativado, vinculado ao menos-phi, símbolo da castração, é aquele que é proibido pela lei da linguagem, o que determina a condição humana à qual pretende escapar - em parte - o sujeito perverso, que põe em jogo um gozo que apresenta como positivo, qualquer coisa que o conforta numa posição de mestria, numa posição fálica, mas que se pode também declinar de outra maneira do lado de um gozo Outro, que não está contudo completamente separado da dimensão fálica. Um gozo que associa ao mesmo tempo que há um que escapa à castração (e o sujeito perverso é bem esse) e que não todo com o seu próprio corpo foi submetido à castração (o que é aqui a marca da perversão no feminino). "O perverso", diz Lacan (1969), "é aquele que se consagra a fechar o buraco no Outro" (p. 253), a 
R E V I S T A

LATINOAMERICANA

DE PSICOPATOLOGIA

F U N D A E N T A L

completá-lo e a pretender restituir-lhe o gozo que ele pensa ter sido privado. Tentamos mostrar que há, finalmente, duas maneiras de fechar esse buraco no Outro: uma masculina, pela restituição do falo a quem não o tem, e uma feminina, que põe em evidência uma dimensão Outra - a do corpo, do homicídio do eu ou do outro, homicídio simbólico ou real do narcisismo e da morte - dimensão na qual o parceiro é arrastado, apesar de si mesmo, pelo outro, não esburacado, uma em que todo o corpo não foi tomado no processo da alienação.

\section{Referências}

Abelhauser, A. (2013). Mal de femme. La perversion au féminin. Paris: Seuil.

Aulagnier, P. (1967). Remarques sur la féminité et ses avatars. In Le désir et la perversion. Paris: Seuil.

Castanet, D. (2003). La perversion au féminin. L'En-je lacanien, (1), 83-94.

Castanet, H. (2012). La perversion. Paris: Économica-Anthropos.

Chaperon, S. (2008). La médecine du sexe et les femmes. Anthologie des perversions féminines au XIXe siècle. Coll. L'Attrape-corps. Paris: La Musardine.

David, C (1972). La perversion affective. In La sexualité perverse, études psychanalytiques. Paris: Payot.

De M’Uzan, M. (1977). Un cas de masochisme pervers. Esquisse d'une théorie. In De l'art à la mort. Paris: Gallimard. (Trabalho original publicado em 1972).

Dor, J. (1987). Structure et perversions. Paris: Denoël.

Ey, H. (1950). Perversité et perversions, Étude n. 13. In Études psychiatriques. Paris: Desclée de Brouwer.

Faladé, S. (2012). Autour de la chose. Paris: Économica-Anthropos. (Trabalho original publicado em 1993-1994).

Freud, S. (1992). La disparition du complexe d'Edipe. In Ouvres complètes (Vol. XVII). Paris: PUF. (Trabalho original publicado em 1924).

Freud, S. (1994). Fétichisme. In Ouvres complètes (Vol. XVIII). Paris: PUF. (Trabalho original publicado em 1927).

Freud, S. (1996a). Un enfant est battu. In Ouvres complètes (Tomo XV). Paris: PUF. (Trabalho original publicado em 1919).

Freud, S. (1996b). De la psychogenèse d'un cas d'homosexualité féminine. In Ouvres complètes (Tomo XV). Paris: PUF. (Trabalho original publicado em 1920).

Freud, S. (2006). Trois essais sur la théorie sexuelle. In Ouvres complètes (Vol. VI). Paris: PUF. (Trabalho original publicado em 1905).

Freud, S. (2010). Le clivage du moi dans le processus de défense. In Ouvres complètes (Vol. XX). Paris: PUF. (Trabalho original publicado em 1938). 


\section{ARTIGOS}

Granoff, W. \& Perrier, F. (1964). Le problème de la perversion chez la femme et les idéaux féminins. In Le désir et le féminin. Paris: Flammarion, 2002.

Hiltenbrand, J-P. (2009). Perversion. In R. Chemama, B. Vandernersh (ed.), Dictionnaire de la psychanalyse. Paris: Larousse.

Kestemberg, E., Kestemberg, J., Decobert, S. (1972). La faim et le corps. Paris: PUF.

Klopfert, D. (2010). Inceste maternel, incestuel meurtrier. À corps et sans cri. Paris: L'Harmattan.

Korff-Sausse, S. (2003). La femme du pervers narcissique. Revue française de psychanalyse, 67 (3), 925-942.

Krafft-Ebing, R. von (1963). Psychopathia sexualis. Paris: Payot. (Trabalho original publicado em 1923).

Lacan, J. (1959). Le séminaire. Livre VI. Le désir et son interprétation. Inédit.

Lacan, J. (1966a). Propos directifs pour un congrès sur la sexualité féminine. In Écrits. Paris: Seuil. (Trabalho original publicado em 1960).

Lacan, J. (1966b). Kant avec Sade. In Écrits. Paris: Seuil. (Trabalho original publicado em 1963).

Lacan, J. (1967). Le séminaire. Livre XIV. La logique du fantasme. Inédit.

Lacan, J. (1972). Séminaire. Le savoir du psychanalyste. Inédit.

Lacan, J. (1975). Le séminaire. Livre XX. Encore. Paris: Seuil. (Trabalho original publicado em 1973).

Lacan, J. (1976). Note liminaire. In La scission de 1953, supplément à la revue Ornicar?, (7).

Lacan, J. (1981). Le séminaire. Livre III. Les psychoses. Paris: Seuil. (Trabalho original publicado em 1955-1956).

Lacan, J. (1991). Le séminaire. Livre XVII. L'envers de la psychanalyse. Paris: Seuil. (Trabalho original publicado em 1970).

Lacan, J. (1998). Le séminaire. Livre V. Les formations de l'inconscient. Paris: Seuil. (Trabalho original publicado em 1958).

Lacan, J. (2005). Le séminaire. Livre XXIII. Le sinthome. Paris: Seuil. (Trabalho original publicado em 1975-1976).

Lacan, J. (2006). Le séminaire. Livre XVI. D’un autre à l'Autre. Paris: Seuil. (Trabalho original publicado em 1969).

Lebrun, J-P. (2007). Perversions ordinaires. Vivre ensemble sans autrui. Paris: Denoël.

Leguil, F. (2012). Préface. In H. Castanet, La perversion. Paris: Économica-Anthropos.

Martin-Mattera, P. (2005). Théorie et clinique de la création. Paris: Économica-Anthropos.

Martin-Mattera, P., Savinaud, C. (2011). Victimation et abus sexuels: présentation clinique et réflexions sur la perversion. In P. Martin-Mattera (ed.), Violences et victimation. Villeneuve d'Ascq: Presses universitaires du Septentrion.

Melman, C. (2005). L'homme sans gravité. Paris: Gallimard.

Racamier, P-C. (1986). Entre agonie psychique, déni psychotique et perversion narcissique. Revue française de psychanalyse, 50(5), 1299-1309.

Racamier, P-C. (1987). De la perversion narcissique. Gruppo, Revue de psychanalyse groupale, (3), 11-27. 
R E V I $\quad$ S $T$ T

LATINOAMERICANA

DE PSICOPATOLOGIA

F U N D A E N T A L

Rivière, J. (1929). Womanliness as a Masquerade. International Journal of Psychoanalysis, 10(23), 303-313.

Sibony, D. (2000). Perversions. Dialogues sur les folies actuelles. Paris: Seuil. (Trabalho original publicado em 1987).

Sirois, F. (1999). La perversion: de part et d'autre du sexe. Canadian Journal of. Psychoanalysis, $7(2), 271-296$.

Soler, C. (2003). Ce que Lacan disait des femmes. Paris: Éditions du Champ Lacanien.

Valas, P. (2012). De la perversion VI. Recuperado em 23 abr 2013 de: <http://www.valas.fr/IMG/ pdf/de_la_perversion_top_nouveau.pdf $>$.

\section{Resumos}

(Perversion in women or female perversion. A matter of sexuation)

The question of the gender of perversion stems from a necessarily social issue. Polymorphous, pathological and structural perversions are the three approaches we focus on here to examine the notions of sexuation, perversion and their intersections. Is perversion gendered? Is it specifically inherent to male or female styles? Can we talk about male perversion on the one hand and female perversion on the other?

Key words: Perversion, sexuation, femininity, psychoanalysis

(Perversion chez les femmes ou perversion féminine. Une question de sexuation)

La question du sexe de la perversion ressort d'une problématique forcément sociale. La perversion polymorphe, la perversion pathologique et la perversion structurale sont les trois modalités d'approche qui nous intéresserons ici pour croiser les notions de sexuation et de perversion. La perversion est-elle genrée, appartient-elle spécifiquement à un style masculin ou féminin, ou est-ce qu'il existe, d'une part, une perversion masculine et, d'autre part, une perversion féminine?

Mots clés: Perversion, sexuation, féminité, psychanalyse

(Perversión en las mujeres o perversión femenina. Una cuestión de sexuación)

La cuestión del sexo de la perversión forzosamente tiene que ver con una problemática social. Perversión polimorfa, perversión patológica, perversión estructural: son tres enfoques que combinaremos con los conceptos de sexuación y perversión. ¿Tiene género la perversión? ¿Pertenece específicamente a un estilo masculino o femenino? ¿Existe una perversión masculina y otra femenina?

Palabras clave: Perversión, sexuación, feminidad, psicoanálisis 


\section{ARTIGOS}

(Perversion der Frauen oder weibliche Perversion. Eine Frage der Sexuation)

Die Frage nach dem Geschlecht der Perversion entstammt zwangsläufig einer sozialen Problematik. Polymorphe Perversion, pathologische Perversion und strukturelle Perversion sind die drei Ansatzweisen, die uns hier zur Gegenüberstellung der Auffassungen von Sexuation und Perversion interessieren. Ist die Perversion geschlechtsspezifisch? Gehört sie eher zum männlichen oder zum weiblichen Stil, oder gibt es gar eine männliche Perversion und eine weibliche Perversion?

Schlüsselwörter: Perversion, Sexuation, Weiblichkeit, Psychoanalyse

Citação/Citation: Martin-Mattera, P. (2014, setembro). Perversão nas mulheres ou perversão feminina. Uma questão de sexuação. Revista Latinoamericana de Psicopatologia Fundamental, 17(3-Suppl.), 720-737.

Editor do artigo/Editor: Prof. Dr. Manoel Tosta Berlinck

Recebido/Received: 15.3.2014/ 3.15.2014 Aceito/Accepted: 15.4.2014 / 4.15.2014

Copyright: (C) 2009 Associação Universitária de Pesquisa em Psicopatologia Fundamental/ University Association for Research in Fundamental Psychopathology. Este é um artigo de livre acesso, que permite uso irrestrito, distribuição e reprodução em qualquer meio, desde que o autor e a fonte sejam citados / This is an open-access article, which permits unrestricted use, distribution, and reproduction in any medium, provided the original author and source are credited.

Financiamento/Funding: $\mathrm{O}$ autor declara não ter sido financiado ou apoiado / The author have no support or funding to report.

Conflito de interesses/Conflict of interest: $\mathrm{O}$ autor declara que não há conflito de interesses / The author has no conflict of interest to declare.

\section{Patrick Martin-Mattera}

Psychologue et psychanalyste; Professeur de psychopathologie, LUNAM Université, Université catholique de l'Ouest - UCO - Institut de psychologie et sociologie appliquées (IPSA); Laboratoire multi-site E.A. 4050: "Recherches en psychopathologie: nouveaux symptômes et lien social"; composante Recherches Clinique psychanalytique, processus psychiques, et esthétique.

3 place André Leroy, BP 10808, 49008 ANGERS Cedex 01

France.

e-mail: martinmattera@wanadoo.fr 